\title{
Coccidioidomycosis and COVID-19 Co-Infection, United States, 2020
}

\author{
Alexandra K. Heaney, Jennifer R. Head, Kelly Broen, Karen Click, \\ John Taylor, John R. Balmes, Jon Zelner, Justin V. Remais
}

We review the interaction between coronavirus disease (COVID-19) and coccidioidomycosis, a respiratory infection caused by inhalation of Coccidioides fungal spores in dust. We examine risk for co-infection among construction and agricultural workers, incarcerated persons, Black and Latino populations, and persons living in high dust areas. We further identify common risk factors for co-infection, including older age, diabetes, immunosuppression, racial or ethnic minority status, and smoking. Because these diseases cause similar symptoms, the COVID-19 pandemic might exacerbate delays in coccidioidomycosis diagnosis, potentially interfering with prompt administration of antifungal therapies. Finally, we examine the clinical implications of co-infection, including severe COVID-19 and reactivation of latent coccidioidomycosis. Physicians should consider coccidioidomycosis as a possible diagnosis when treating patients with respiratory symptoms. Preventive measures such as wearing face masks might mitigate exposure to dust and severe acute respiratory syndrome coronavirus 2 , thereby protecting against both infections.

Dersons with coronavirus disease (COVID-19) 1 can have a wide range of symptoms, including cough, difficulty breathing, and fatigue (1). These symptoms are also common among patients with coccidioidomycosis (2), a primarily pulmonary disease caused by inhalation of Coccidioides, a soildwelling dimorphic fungi. These spores spread through the air, especially through wind erosion in dusty environments and dirt disrupting activities such as digging or construction. Coccidioides spores are found in hot and arid environments, including much of the southwestern United States, where coccidioidomycosis incidence has been increasing.

Author affiliations: University of California, Berkeley, California, USA (A.K. Heaney, J.R. Head, K. Click, J. Taylor, J.R. Balmes, J.V. Remais); University of Michigan, Ann Arbor, Michigan, USA (K. Broen, J. Zelner); University of California, San Francisco, California, USA (J.R. Balmes)

DOI: https://doi.org/10.3201/eid2705.204661
Since 2016, California has recorded its highest incidences of coccidioidomycosis $(3,4)$.

We reviewed epidemiologic and clinical literature on coccidioidomycosis and COVID-19 to identify subpopulations that might be at risk for co-infection and severe disease. We discuss how the COVID-19 pandemic might affect coccidioidomycosis diagnosis, surveillance, and clinical management. We also evaluate evidence that co-infection might contribute to severe COVID-19 or reactivation of latent Coccidioides infection. Our study informs healthcare providers, policymakers, and populations in regions to which coccidioidomycosis is endemic on potential interactions between this disease and COVID-19, encouraging protective measures and prompt diagnosis.

\section{Methods}

We searched peer-reviewed journals on PubMed, Google Scholar, Scopus, and Web of Science; preprints posted on medRxiv and bioRxiv; and reports from state health departments and correctional agencies for articles on risk factors for infection and disease severity, diagnosis, surveillance, and preventive measures for coccidioidomycosis and COVID-19. We assessed titles and abstracts for relevance to the risk factors, diagnostic issues, and complications of coccidioidomycosis and COVID-19 co-infections. We conducted searches published during April-December 2020 and did not exclude articles on the basis of publication date. We identified other relevant publications by backward citation searching. We analyzed 116 peer-reviewed articles, 4 preprints, and 28 reports.

\section{Possible Risk Factors for Coccidioidomycosis and COVID-19}

COVID-19 and coccidioidomycosis share certain risk factors for exposure, potentially increasing the risk for co-infection. In California and Arizona, the 2 states with the highest number of reported coccidioidomycosis cases, substantial overlap exists between 
county-level incidence of COVID-19 in 2020 and coccidioidomycosis in 2019 (Figures 1, 2).

\section{Occupational Risks}

Certain occupations pose increased risk for coccidioidomycosis. Because soil disruption and dusty environments promote dispersal of Coccidioides spores, coccidioidomycosis outbreaks frequently occur among workers in the construction and agricultural sectors $(8,9,10)$. Of 47 coccidioidomycosis outbreaks reported during 1940-2015, a total of 25 (53\%) were associated with occupational exposure, including 15 $(60 \%)$ that were related to construction (11). An analysis of workers' compensation claims found that the incidence of coccidioidomycosis related to occupational exposure nearly quadrupled in California during 2000-2006, the highest rates seen among construction and agricultural workers (12).

Continued in-person work within the construction and agricultural sectors, which are considered essential occupations, also increases risk for COVID-19. In the United States, an estimated $8 \%$ of construction workers have had workplace exposure to the causative agent of COVID-19, severe acute respiratory syndrome coronavirus 2 (SARS-CoV-2), at least monthly, and nearly $60 \%$ of the construction labor force has $\geq 1$ risk factor for severe COVID-19 (13, 14). Agricultural workers might also have heightened risk for COVID-19 because of high workforce turnover, shared transportation, and overcrowded living quarters that are often shared with other workers, multigenerational families, or both (15-19).

\section{Incarcerated Populations}

Incarcerated persons have a high risk for exposure to Coccidioides spores and SARS-CoV-2. Prisons and other facilities, such as immigration detention centers, are often in isolated areas with high environmental dust concentrations that can place inmates at higher risk for Coccidioides infection (Appendix, https:// wwwnc.cdc.gov/EID/article/27/5/20-4661-App1. pdf). In addition, crowding, unsanitary conditions, and poor ventilation in carceral environments contributes to the rapid spread of communicable respiratory diseases like COVID-19 (20). Researchers have documented COVID-19 outbreaks among fire-fighting crews composed of incarcerated persons (21); similarly, researchers documented 7 coccidioidomycosis outbreaks among such fire-fighting crews during 2000-2017 (22). During 1940-2015, a total of 5 (11\%) reported coccidioidomycosis outbreaks were among incarcerated populations (11). During 2007-2011, a total of $19 \%$ of coccidioidomycosis cases in California were among incarcerated persons (23). More than 25\% of California Department of Corrections and Rehabilitation facilities, including Lompoc Prison Complex (Lompoc, CA, USA), where a COVID-19 outbreak infected $>1,000$ persons (24), are in regions with high coccidioidomycosis incidence (25).

Researchers have documented several outbreaks of COVID-19 in carceral facilities (Appendix). During January 21-April 21, 2020, a total of $82 \%$ of reporting state and territorial health department jurisdictions reported confirmed COVID-19 cases among incarcerated or detained persons (including 4,893 reported
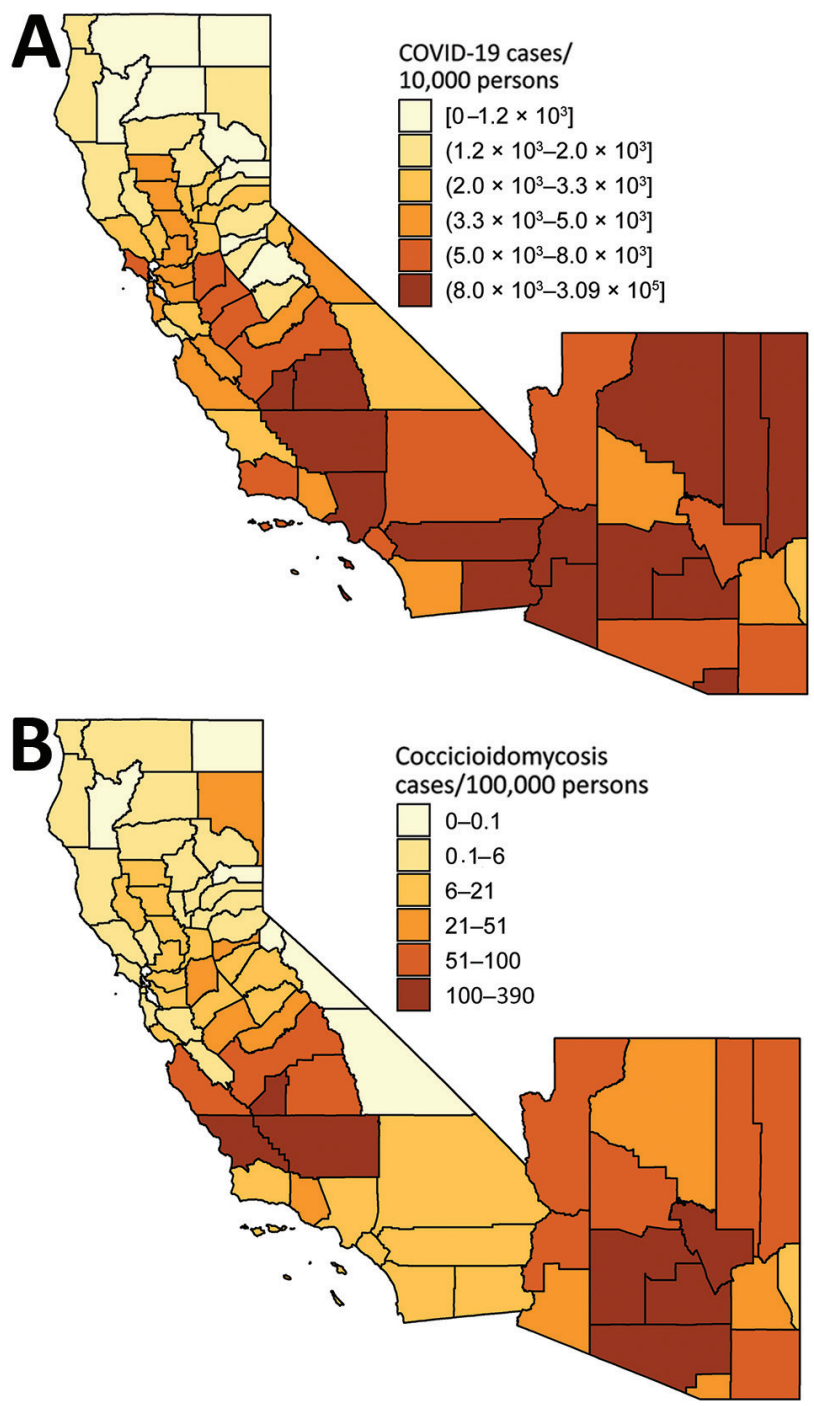

Figure 1. County-level incidence of $(A)$ coronavirus disease (COVID-19) in 2020 and (B) coccidioidomycosis in 2019, California and Arizona. COVID-19 incidence reflects cumulative case count as of August 14, 2020 (5). Coccidioidomycosis incidence reflects annual incidence in $2019(6,7)$. Shading indicates levels of incidence. Brackets indicate inclusive bounds; parentheses indicate exclusive bounds. 


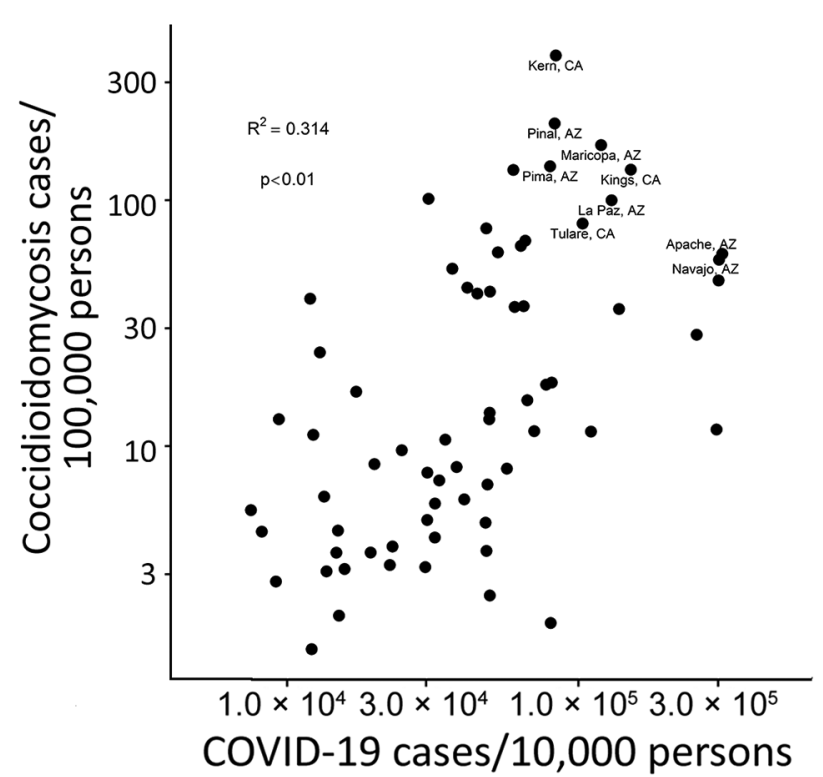

Figure 2. Scatterplot of county-level incidence of COVID-19 in 2020 and coccidioidomycosis in 2019, California and Arizona. $\mathrm{R} 2=0.259 ; \mathrm{p}<0.01$.

cases and 88 deaths) or staff members (including 2,778 reported cases and 15 deaths) (26). COVID-19 outbreaks affecting $>1,000$ persons have occurred among incarcerated persons and staff working at carceral facilities in states from California to New York (Appendix).

\section{Racial and Ethnic Minorities}

Substantial racial and ethnic disparities exist in COVID-19 and coccidioidomycosis infection rates. Persons of Black and Latino heritage are at heightened risk for these infections. In California as of February 2021, Latino persons comprise $39 \%$ of the total population but account for $55 \%$ of COVID-19 cases (27). In the United States, COVID-19 incidence and death rates in counties with predominantly Black populations are significantly higher than in counties with predominantly white populations (28). In addition, Latino persons comprise $39 \%$ of the California population but $47 \%$ of its coccidioidomycosis patients; in the same state, non-Hispanic Black persons comprise $6 \%$ of the population but $9 \%$ of coccidioidomycosis patients (3).

Numerous societal inequities (including racism and discrimination, economic and educational disadvantages, and lack of healthcare access) contribute to higher pathogen exposure and infection rates among Black and Latino populations (29). In the context of the COVID-19 pandemic, social distancing might be more difficult for persons of low socioeconomic status because of their overrepresentation in essential occupations, elevated risk of living in densely populated homes and neighborhoods, and higher numbers of multigenerational households (15-19). For example, $55 \%$ of Latino and $48 \%$ of Black persons work in essential jobs, compared with $35 \%$ of White persons (30). Disparities in coccidioidomycosis rates might also be caused by the disproportionate numbers of Black and Latino persons who are incarcerated or work in occupations with high exposure risk. More than $50 \%$ of farm laborers, agricultural workers, and construction workers in California are Latino $(31,32)$. In addition, Black and Latino persons are overrepresented in carceral facilities: in California, Black persons comprise $27 \%$ and Latino persons comprise $41 \%$ of jail and prison populations (33).

\section{Exposure to Particulate Matter}

Persons living in environments with high concentrations of dust, which is a major constituent of particulate matter $\leq 10 \mu \mathrm{m}$ or $\leq 2.5 \mu \mathrm{m}$ in diameter, might be at elevated risk for infection with Coccidioides and SARS-CoV-2 and severe illness from COVID-19. Exposure to particulate matter is a risk factor for illness and death from viral respiratory infections, including COVID-19 (Appendix). Exposure to outdoor particulate air pollution is also associated with Coccidioides infection because mineral dust can mobilize airborne spores $(34,35)$. Coccidioidomycosis outbreaks have been linked to dust plumes generated by military exercises, agriculture, construction, archeology excavations, windstorms, and landslides (36-43). For example, in an outbreak affecting 89 persons at a solar farm, persons who reported being in a dust cloud had $\approx 6$ times the odds of symptomatic coccidioidomycosis than those who were not in the dust cloud. Wetting the dirt before soildisrupting activities, a common practice to reduce dust, decreased the odds of symptomatic infection by $58 \%$ (44). Because COVID-19 control measures encourage the use of outdoor spaces, persons might have increased exposures to mineral dust and other air pollutants during the pandemic.

\section{Co-Circulation with SARS-CoV-2 Hampering Coccidioidomycosis Diagnosis}

The diagnosis of coccidioidomycosis in areas with community transmission of COVID-19 might be challenging because the diseases cause similar symptoms, which might exacerbate existing delays in coccidioidomycosis diagnosis and treatment. Without antifungal treatment, coccidioidomycosis patients are at risk for severe illness, including disseminated disease, and for death (45). Promptly administering antifungal treatments reduces unnecessary use of antimicrobial drugs 
and resolves symptoms more effectively (45). In addition, early case management, including assessing risk factors for severity, regular follow-up visits to monitor symptoms, regular testing to check antibody titer levels, and physical therapy, is crucial to mitigating severe disease (46).

One reason for the underdiagnosis of coccidioidomycosis is low testing rates. For instance, a study in Tucson, Arizona, estimated that $15 \%-44 \%$ of community-acquired pneumonia cases could be attributed to coccidioidomycosis (47), but only $2 \%-13 \%$ of community-acquired pneumonia cases were tested for coccidioidomycosis (48). Valdivia et al. (47) found that half of patients had $\geq 2$ clinic visits before being tested for coccidioidomycosis. Low sensitivities of coccidioidomycosis tests might further contribute to delays in diagnosis (Appendix). Given such diagnostic constraints, the median time between seeking healthcare and coccidioidomycosis diagnosis was estimated to be 23 days in Arizona (49).

The COVID-19 pandemic might contribute to further delays in coccidioidomycosis diagnosis. Both diseases can cause dry cough, muscle aches, headache, fatigue, and difficulty breathing; however, patients with COVID-19 tend to have a more acute progression of symptoms than those with coccidioidomycosis (50; Appendix references 51-54). Although pulmonary specialists and primary care physicians in regions to which coccidioidomycosis is endemic are probably aware of the diagnosis and treatment of this fungal infection, physicians in other regions might be less familiar with the diagnosis. Attributing coccidioidomycosis symptoms to COVID-19, whether presumed or laboratory-confirmed, might preclude coccidioidomycosis diagnosis in patients with monoinfections or co-infections. In addition, underutilization of healthcare services during the COVID-19 pandemic might result in further delays in the testing and diagnosis of coccidioidomycosis (Appendix reference 55).

\section{Risk Factors for Severe Disease}

Although most cases of coccidioidomycosis or COVID-19 are mild respiratory illnesses, either infection can cause severe disease and death (Appendix). Risk factors associated with severe coccidioidomycosis or COVID-19 often overlap, prompting concerns of elevated death rates associated with co-infections or serial infections. Patients with SARS-CoV-2 and Coccidioides co-infection might be at higher risk for severe disease; however, whether synergistic effects might exist requires further data. Overlapping risk factors associated with severe disease caused by coccidioidomycosis or COVID-19 include older age, diabetes mellitus, immunosuppression, Black/African American ancestry, and smoking (Appendix references 56-70). Although the long-term pulmonary effects of COVID-19 remain unknown, early data suggest that the virus might cause lung damage (Appendix reference 71), resulting in elevated long-term risk for severe coccidioidomycosis.

\section{Age}

Older persons have heightened risk for severe disease caused by either infection. In the United States, $62 \%$ of COVID-19 hospitalizations and $80 \%$ of deaths were among patients $>65$ years of age (Appendix reference 72). Similarly, older persons, especially those $>65$ years of age, with coccidioidomycosis have higher risk for severe pulmonary disease. Rates of coccidioidomycosis-associated death increase with age. These trends might be partially explained by the higher prevalence among older adults of preexisting conditions and immunosuppression, which are risk factors for severe COVID-19 and coccidioidomycosis (Appendix references 56-64).

\section{Diabetes}

Diabetes is also associated with severe progression of either disease (Appendix references 56,63-68). A study of COVID-19 patients found that those with diabetes had a higher risk for severe pneumonia and organ damage (Appendix reference 73). The study also showed that patients with diabetes were more susceptible to a SARS-CoV-2-induced cytokine storm, which can cause rapid deterioration and death (Appendix reference 73). In addition, patients with diabetes are more likely to have relapsing coccidioidomycosis (risk ratio [RR] 3.39, 95\% CI 1.65-6.46) or cavitary lung disease (RR 2.94, 95\% CI 1.63-4.90) than those without diabetes (Appendix reference 74). Furthermore, among coccidioidomycosis patients with diabetes, those with higher serum glucose levels are more likely to have disseminated coccidioidomycosis, the most severe form of the disease, than those with lower levels (Appendix reference 74 ). The exact mechanisms through which diabetes influences the progression of coccidioidomycosis and COVID-19 are not well understood but might be related to impaired innate and adaptive cellular immunity (especially T-cell function) or the effects of a hyperglycemic environment on microorganism virulence (Appendix reference 75).

\section{Immunosuppression}

Although immunosuppressive steroids such as dexamethasone have reduced inflammatory lung 
damage in patients with severe COVID-19 (Appendix reference 76), emerging evidence suggests that persons with a history of prolonged immunosuppression might be at higher risk for severe COVID-19. A study of 17 million adults in the United Kingdom found higher risks for death among COVID-19 patients who have hematologic malignancies, who are taking immunosuppressant drugs for organ transplants, or who have other causes of immunosuppression (Appendix reference 77). Immunosuppressed patients with cancer or solid organ transplants might be at higher risk for severe COVID-19 (Appendix reference 78). Coccidioidomycosis patients with suppressed immune responses, such as patients with hematologic malignancies, HIV, or organ transplants, also have higher risk for disseminated disease (Appendix references 61-63).

\section{Black/African American Ancestry}

Black persons have higher rates of severe COVID-19 and disseminated coccidioidomycosis than do White persons. Growing evidence indicates higher risk for severe COVID-19-associated disease and death among Black than White persons living in the United States (Appendix). A study of coccidioidomycosis in military personnel found dissemination rates to be 10 times higher among Black than White persons (Appendix reference 79). Similarly, a study in Kern County, California, found that patients with disseminated coccidioidomycosis were 4.6 times more likely to be Black than patients with mild disease (Appendix reference 56). The observed racial and ethnic disparities in severe COVID-19 and coccidioidomycosis are probably driven by structural inequities that systematically disadvantage persons of color in the forms of reduced healthcare access and exposure to environmental stressors that increase risk for conditions such as diabetes, obesity, and hypertension, which are associated with severe disease (29). For coccidioidomycosis, whether any biological basis for this association exists is unclear but might be related to immunogenic differences in T-cell function (Appendix references 56,69,70).

\section{Smoking}

Recent history of cigarette smoking has been linked to higher risk for severe disease from either infection. A systematic review and meta-analysis found that smokers with COVID-19 were significantly more likely (RR 2.4, 95\% CI 1.43-4.04) to be admitted to an intensive care unit, need mechanical ventilation, or die compared with nonsmokers (Appendix reference 80). A case-control study in Kern County found that patients with severe or disseminated coccidioidomycosis were more likely to have smoked cigarettes in the previous 6 months compared with patients with mild coccidioidomycosis (Appendix reference 56).

\section{Possible Effects of Co-Infection on Disease Progression}

\section{Severe COVID-19}

Underlying respiratory illness is a major risk factor for severe COVID-19 (Appendix references 60,64). The Centers for Disease Control and Prevention reported that among COVID-19 patients in the United States with available data on concurrent conditions, 9.2\% had a chronic lung disease such as chronic obstructive pulmonary disease, asthma, or emphysema; chronic lung disease was the most common concurrent condition after diabetes (Appendix reference 81 ). The prevalence of chronic lung disease is higher among hospitalized patients (15\%) and highest among patients in the intensive care unit (21\%) (Appendix reference 81). Several studies of COVID-19 patients in China have also shown elevated rates of death and severe disease among those with underlying chronic respiratory conditions (Appendix references $64,82,83$ ). Acute coccidioidomycosis is often self-limiting, but $\approx 3 \%-5 \%$ of patients have a chronic pulmonary form of the illness (Appendix references 84,85 ). The evidence that chronic lung disease increases risk for severe COVID-19 suggests that patients with chronic pulmonary coccidioidomycosis might be predisposed to severe COVID-19.

\section{Coccidioidomycosis Reactivation}

Infection with COVID-19 might reactivate disease in a coccidioidomycosis patient whose illness has progressed to a chronic but inactive state. After an initial Coccidioides infection resolves, the fungus can remain in the lungs in a latent state and become reactivated under certain conditions (Appendix references 86-93). Coccidioidomycosis reactivation has been reported among pregnant women, especially those who previously had disseminated coccidioidomycosis (Appendix reference 94). Patients with organ transplants, which usually require immunosuppressive medications, also have higher rates of coccidioidomycosis reactivation (Appendix references 87-92). SARS-CoV-2 infection has been associated with immune dysregulation, including lymphopenia (Appendix reference 95), which might lower the host's ability to regulate Coccidioides infection (Appendix reference 96). Although no studies have reported coccidioidomycosis reactivation in COVID-19 patients 
as of February 2021, emerging evidence suggests that COVID-19 infection might accelerate the reactivation of latent tuberculosis (L. Pathak, unpub. data, https:/ / www.biorxiv.org/content/10.1101/2020.05 $.06 .077883 v 2$ ). In addition, dexamethasone, a medication recommended for patients with severe COVID-19, increases the risk for severe coccidioidomycosis (Appendix references 97,98).

\section{Areas for Future Research}

\section{Cloth Masks}

Although cloth masks are a critical control method for COVID-19 (Appendix), studies have not examined the efficacy of cloth masks for filtering Coccidioides arthroconidia. At 2-5 $\mu \mathrm{m}$ in diameter, Coccidioides arthroconidia are substantially larger than SARS-CoV-2; this size difference might lead to differing levels of filtration effectiveness (Appendix references 99,100). One study found that cloth masks containing tightly woven cottons can filter $98 \%$ of particles in the $300 \mathrm{~nm}-6$ $\mu \mathrm{m}$ range (Appendix reference 101), yet such results are difficult to extrapolate to specific particles such as Coccidioides arthroconidia (Appendix reference 102). It is also difficult to extrapolate results to other cloth masks, which vary widely in their filtration properties. Furthermore, leakage from improperly fitting masks can reduce efficacy of particle filtration by up to 50\% (Appendix reference 101). The effects of leakage on disease prevention might differ on the basis of infectious dose; although a single Coccidioides spore might confer infection, the infectious dose of SARS$\mathrm{CoV}-2$ is probably higher. California therefore requires employers with worksites in regions to which coccidioidomycosis is endemic to provide respiratory protection filters rated at least N95 to workers if dust cannot be controlled; no mask recommendation exists for the general public (Appendix reference 103).

\section{Climate}

Transmission of SARS-CoV-2 and Coccidioides spores might be influenced by climatic conditions, such as temperature and humidity, that can affect pathogen survival and transport. For example, high humidity can suppress aerosol transmission of respiratory pathogens such as influenza and respiratory syncytial virus (Appendix references 104-110). Early research in Wuhan, China, suggested that SARS-CoV-2 might be transmitted more efficiently in less humid environments (Appendix references 111-113; W. Luo, unpub. data, https://www.medrxiv.org/content/10.1101/2020. 02.12.20022467v1). Although the influence of temperature and other climatic conditions on transmission and seasonality of SARS-CoV-2 currently might be outweighed by the large size of the susceptible population, the introduction of a vaccine could result in patterns of population immunity that enable climate to play a larger moderating role (Appendix reference 114). Because relative humidity plays a major role in regulating atmospheric dust concentrations, high atmospheric moisture can limit the dispersal of Coccidioides spores, potentially suppressing coccidioidomycosis transmission. For example, under wind conditions strong enough to mobilize dust, increases in relative humidity were associated with decreasing atmospheric dust concentrations (Appendix reference 115).

\section{Disparities in Surveillance}

The extent of socioeconomic, demographic, racial, and other disparities in COVID-19 and coccidioidomycosis is probably greater than reflected in administrative data sources. For example, analyses from hard-hit regions have indicated that high rates of excess death probably reflect a large burden of unreported SARS-CoV-2 infection (Appendix reference 116; J. Felix-Cardoso, unpub. data, https://www. medrxiv.org/content/10.1101/2020.04.28.2008314 $7 \mathrm{v} 1)$. Although testing coverage for SARS-CoV-2 is increasing, infections will probably continue to be undercounted in certain regions and populations because of factors such as disparate healthcare access, reagent shortages, and varied willingness to get tested. Undocumented or migrant farmworkers at high risk for exposure to Coccidioides spores are mostly uninsured, ineligible for healthcare benefits, or unable to afford healthcare (Appendix reference 117,118). The disparities seen in rates of illness and death caused by COVID-19 and coccidioidomycosis might have many contributing factors, including barriers to affordable, high-quality, and accessible healthcare; occupational exposures; mass incarceration; residential segregation; discrimination; and differential rates of concurrent conditions. Understanding these disparities is critical for attracting the attention and resources needed to remedy inequities in exposures, care-seeking, and illness and death caused by coccidioidomycosis and COVID-19.

\section{Conclusions}

Public health professionals, healthcare providers, and populations in areas to which coccidioidomycosis is endemic should be aware of the overlap in risk factors for coccidioidomycosis and COVID-19. Because prompt diagnosis is critical for effective management of coccidioidomycosis and the COVID-19 pandemic might exacerbate existing delays, 
healthcare professionals should know how to identify these diseases and potential co-infection. Agricultural and construction workers, firefighters, Black and Latino persons, persons with diabetes, elderly persons, incarcerated persons, and migrant or undocumented farmworkers might be at increased risk for coccidioidomycosis and COVID-19. Employers and public health officials should mitigate exposure to dust and SARS-CoV-2 by promoting the use of face masks and social distancing practices.

This research was supported in part by the National Science Foundation (grant no. 2032210), the National Institutes of Health (grant nos. R01AI125842 and R01AI148336), and the University of California Multicampus Research Programs and Initiatives (award no. 17-446315).About the Author

Dr. Heaney is a postdoctoral scholar at the University of California, Berkeley, California, USA. Her research interests include the epidemiology and environmental determinants of infectious diseases.

\section{References}

1. Goyal P, Choi JJ, Pinheiro LC, Schenck EJ, Chen R, Jabri A, et al. Clinical characteristics of Covid-19 in New York City. N Engl J Med. 2020;382:2372-4. https:// doi.org/10.1056/ NEJMc2010419

2. Blair JE, Chang YHH, Cheng MR, Vaszar LT, Vikram HR, Orenstein R, et al. Characteristics of patients with mild to moderate primary pulmonary coccidioidomycosis. Emerg Infect Dis. 2014;20:983-90. https:/ / doi.org/10.3201/ eid2006.131842

3. California Department of Public Health. Epidemiological summary of coccidioidomycosis in California, 2018. 2019 [cited 2020 May 18]. https://www.cdph.ca.gov/Programs/ CID/DCDC/CDPH\%20Document\%20Library/ CocciEpiSummary2018.pdf

4. Centers for Disease Control and Prevention. Valley fever (coccidiomycosis) statistics. 2020 [cited 2020 May 14]. https:/ / www.cdc.gov/fungal/diseases/coccidioidomycosis/ statistics.html

5. USAFacts. US coronavirus cases and deaths by state. 2020 [cited 2020 May 21]. https://usafacts.org/visualizations/ coronavirus-covid-19-spread-map

6. California Department of Public Health. Coccidioidomycosis in California provisional monthly report: January-April 2020. 2020 [cited 2020 May 28]. https:/ / www.cdph.ca.gov/ Programs/CID/DCDC/CDPH\%20Document\%20Library/ CocciinCAProvisionalMonthlyReport.pdf

7. Arizona Department of Health Services. Valley fever 2019 annual report. 2021 [cited 2021 Feb 24]. https:/ / www.azdhs. gov/documents/preparedness/epidemiology-diseasecontrol/valley-fever/reports/valley-fever-2019.pdf

8. Levan NE, Huntington RW. Primary cutaneous coccidioidomycosis in agricultural workers. Arch Dermatol. 1965;92:215-20. https:/ / doi.org/10.1001/ archderm.1965.01600150005001

9. Schmelzer LL, Tabershaw IR. Exposure factors in occupational coccidioidomycosis. Am J Public Health Nations Health. 1968;58:107-13. https:/ / doi.org/10.2105/ AJPH.58.1.107
10. Johnson WM. Occupational factors in coccidioidomycosis. J Occup Med. 1981;23:367-74.

11. Freedman M, Jackson BR, McCotter O, Benedict K. Coccidioidomycosis outbreaks, United States and worldwide, 1940-2015. Emerg Infect Dis. 2018;24:417-23. https://doi.org/10.3201/eid2403.170623

12. Das R, McNary J, Fitzsimmons K, Dobraca D, Cummings K, Mohle-Boetani J, et al. Occupational coccidioidomycosis in California: outbreak investigation, respirator recommendations, and surveillance findings. J Occup Environ Med. 2012;54:564-71. https:/ / doi.org/10.1097/ JOM.0b013e3182480556

13. Baker MG, Peckham TK, Seixas NS. Estimating the burden of United States workers exposed to infection or disease: a key factor in containing risk of COVID-19 infection. PLoS One. 2020;15:e0232452. https:// doi.org/10.1371/ journal.pone.0232452

14. Brown S, Brooks R, Dong XS. Coronavirus and health disparities in construction. The Center for Construction Research and Training. 2020 [cited 2020 Oct 16]. https:/ /www.cpwr.com/wp-content/uploads/ publications/DataBulletin-May2020.pdf

15. Acs G, Loprest PJ. Job differences by race and ethnicity in the low-skill job market. The Urban Institute. 2009 [cited 2020 Jun 15]. https:/ / www.urban.org/sites/default/files/ publication/30146/411841-Job-Differences-by-Race-andEthnicity-in-the-Low-Skill-Job-Market.PDF

16. Murray CJL, Kulkarni SC, Michaud C, Tomijima N, Bulzacchelli MT, Iandiorio TJ, et al. Eight Americas: investigating mortality disparities across races, counties, and race-counties in the United States [Erratum in: PLoS Med. 2006 Dec;3:e545]. PLoS Med. 2006;3:e260.

https://doi.org/10.1371/journal.pmed.0030260

17. Centers for Disease Control and Prevention. Communities, schools, workplaces, and events. 2020 [cited 2020 Oct 16]. https:/ / www.cdc.gov/coronavirus/2019-ncov/community/ guidance-agricultural-workers.html

18. Arcury TA, Weir M, Chen H, Summers P, Pelletier LE, Galván L, et al. Migrant farmworker housing regulation violations in North Carolina. Am J Ind Med. 2012;55:191-204. https://doi.org/10.1002/ajim.22011

19. Quandt SA, Brooke C, Fagan K, Howe A, Thornburg TK, McCurdy SA. Farmworker housing in the United States and its impact on health. New Solut. 2015;25:263-86. https://doi.org/10.1177/1048291115601053

20. Simpson PL, Simpson M, Adily A, Grant L, Butler T. Prison cell spatial density and infectious and communicable diseases: a systematic review [Erratum in: BMJ Open. 2020;10: e026806corr1]. BMJ Open. 2019;9:e026806. https:/ / doi.org/10.1136/bmjopen-2018-026806

21. Sabalow R, Pohl J. California severely short on firefighting crews after COVID-19 lockdown at prison camps. The Sacramento Bee. 2020 [cited 2020 Aug 18]. https://www.sacbee.com/news/california/fires/ article243977827.html

22. Lucas KD, Wheeler C, Mohle-Boetani JC. Coccidioidomycosis outbreaks among inmate wildland firefighters in California. Proceedings of the 63rd Coccidioidomycosis Study Group Annual Meeting; 2019 Apr 5-6. Sacramento, CA, USA.

23. MacLean M. Epidemiology of coccidioidomycosis - 15 California counties, 2007-2011. 2014 [cited 2020 May 28]. https://www.vfce.arizona.edu/sites/vfce/files/the_ epidemiology_of_coccidioidomycosis_collaborative_ county_report.pdf

24. The New York Times. Coronavirus in the U.S.: latest map and case count. 2020 [cited 2020 May 28]. https:/ / www. 
nytimes.com/interactive/2020/us/coronavirus-us-cases. html?auth=login-email\&login=email

25. Prison Law Office. Valley fever and CDCR housing. 2019 [cited 2020 May 28]. https:/ / prisonlaw.com/wp-content/ uploads/2019/04/Valley-Fever-info-April-2019.pdf

26. Wallace M, Hagan L, Curran KG, Williams SP, Handanagic S, Bjork A, et al. COVID-19 in correctional and detention facilities - United States, February-April 2020. MMWR Morb Mortal Wkly Rep. 2020;69:587-90. https:/ / doi.org/10.15585/mmwr.mm6919e1

27. California Department of Public Health. COVID-19 race and ethnicity data. 2020 [cited 2020 Jun 15]. https:/ / www.cdph. ca.gov/Programs/CID/DCDC/Pages/COVID-19/ Race-Ethnicity.aspx

28. Moore JT, Ricaldi JN, Rose CE, Fuld J, Parise M, Kang GJ, et al. Disparities in incidence of COVID-19 among underrepresented racial/ethnic groups in counties identified as hotspots during June 5-18, 2020 - 22 states, FebruaryJune 2020. MMWR Morb Mortal Wkly Rep. 2020;69:1122-6. https://dx.doi.org/10.15585/mmwr.mm6933

29. Zelner J, Trangucci R, Naraharisetti R, Cao A, Malosh R, Broen K, et al. Racial disparities in COVID-19 mortality are driven by unequal infection risks. Clin Infect Dis. 2020;72:e88-95. https:// doi.org/10.1093/cid/ciaa1723

30. Thomason S, Bernhardt A. Front-line essential jobs in California: a profile of job and worker characteristics. UC Berkeley Labor Center. 2020 [cited 2020 Aug 18]. https:/ /laborcenter.berkeley.edu/front-line-essential-jobsin-california-a-profile-of-job-and-worker-characteristics/

31. United States Department of Agriculture. Farm labor. 2020 [cited 2020 Jun 15]. https:/ / www.ers.usda.gov/topics/ farm-economy/farm-labor/\#demographic

32. United States Census Bureau. Five-year public use microdata sample (PUMS), 2014-2018. 2020 [cited 2020 Jun 15]. https://www.census.gov/programs-surveys/acs/ technical-documentation/pums/documentation.html

33. United States Census Bureau. 2010 census summary file 1. 2016 [cited 2020 Jun 5]. https:/ / www.census.gov/data/ datasets/2010/dec/summary-file-1.html

34. Chow NA, Griffin DW, Barker BM, Loparev VN, Litvintseva AP. Molecular detection of airborne Coccidioides in Tucson, Arizona. Med Mycol. 2016;54:584-92. https:/ / doi.org/10.1093/mmy/myw022

35. Pappagianis D, Einstein H. Tempest from Tehachapi takes toll or Coccidioides conveyed aloft and afar. West J Med. 1978; 129:527-30.

36. Das R, McNary J, Fitzsimmons K, Dobraca D, Cummings K, Mohle-Boetani J, et al. Occupational coccidioidomycosis in California: outbreak investigation, respirator recommendations, and surveillance findings. J Occup Environ Med. 2012;54:564-71. https:/ / doi.org/10.1097/ JOM.0b013e3182480556

37. Cummings KC, McDowell A, Wheeler C, McNary J, Das R, Vugia DJ, et al. Point-source outbreak of coccidioidomycosis in construction workers. Epidemiol Infect. 2010;138:507-11. https://doi.org/10.1017/S0950268809990999

38. Petersen LR, Marshall SL, Barton C, Hajjeh RA, Lindsley MD, Warnock DW, et al. Coccidioidomycosis among workers at an archeological site, northeastern Utah. Emerg Infect Dis. 2004;10:637-42. https://doi.org/10.3201/eid1004.030446

39. Standaert SM, Schaffner W, Galgiani JN, Pinner RW, Kaufman L, Durry E, et al. Coccidioidomycosis among visitors to a Coccidioides immitis-endemic area: an outbreak in a military reserve unit. J Infect Dis. 1995;171:1672-5. https:/ / doi.org/10.1093/infdis/171.6.1672

40. Wilken JA, Sondermeyer G, Shusterman D, McNary J, Vugia DJ, McDowell A, et al. Coccidioidomycosis among workers constructing solar power farms, California, USA, 2011-2014. Emerg Infect Dis. 2015;21:1997-2005. https://doi.org/10.3201/eid2111.150129

41. de Perio MA, Materna BL, Sondermeyer Cooksey GL, Vugia DJ, Su CP, Luckhaupt SE, et al. Occupational coccidioidomycosis surveillance and recent outbreaks in California. Med Mycol. 2019;57:S41-5. https:/ / doi.org/ 10.1093/mmy/myy031

42. Gorris ME, Cat LA, Zender CS, Treseder KK, Randerson JT. Coccidioidomycosis dynamics in relation to climate in the southwestern United States. Geohealth. 2018;2:6-24. https://doi.org/10.1002/2017GH000095

43. Schneider E, Hajjeh RA, Spiegel RA, Jibson RW, Harp EL, Marshall GA, et al. A coccidioidomycosis outbreak following the Northridge, Calif, earthquake. JAMA. 1997;277:904-8. https://doi.org/10.1001/jama.1997. 03540350054033

44. Sondermeyer Cooksey GL, Wilken JA, McNary J, Gilliss D, Shusterman D, Materna BL, et al. Dust exposure and coccidioidomycosis prevention among solar power farm construction workers in California. Am J Public Health. 2017;107:1296-303. https://doi.org/10.2105/ AJPH.2017.303820

45. Galgiani JN, Ampel NM, Blair JE, Catanzaro A, Johnson RH, Stevens DA, et al. Coccidioidomycosis. Clin Infect Dis. 2005;41:1217-23. https://doi.org/10.1086/496991

46. Galgiani JN, Blair JE, Ampel NM, Thompson GR. Treatment for early, uncomplicated coccidioidomycosis: what is success? Clin Infect Dis. 2020;70:2008-12. https://doi.org/10.1093/cid/ciz933

47. Valdivia L, Nix D, Wright M, Lindberg E, Fagan T, Lieberman D, et al. Coccidioidomycosis as a common cause of community-acquired pneumonia. Emerg Infect Dis. 2006;12:958-62. https://doi.org/10.3201/eid1206.060028

48. Chang DC, Anderson S, Wannemuehler K, Engelthaler DM, Erhart L, Sunenshine RH, et al. Testing for coccidioidomycosis among patients with community-acquired pneumonia. Emerg Infect Dis. 2008;14:1053-9. https:/ / doi.org/10.3201/ eid1407.070832

49. Tsang CA, Anderson SM, Imholte SB, Erhart LM, Chen S, Park BJ, et al. Enhanced surveillance of coccidioidomycosis, Arizona, USA, 2007-2008. Emerg Infect Dis. 2010;16:1738-44. https://doi.org/10.3201/eid1611.100475

50. Fu L, Wang B, Yuan T, Chen X, Ao Y, Fitzpatrick T, et al. Clinical characteristics of coronavirus disease 2019 (COVID-19) in China: a systematic review and metaanalysis. J Infect. 2020;80:656-65. https:/ / doi.org/10.1016/ j.jinf.2020.03.041

51. Goyal P, Choi JJ, Pinheiro LC, Schenck EJ, Chen R, Jabri A, et al. Clinical characteristics of Covid-19 in New York City. N Engl J Med. 2020;382:2372-4. https:/ / doi.org/10.1056/ NEJMc2010419

Address for correspondence: Justin Remais, University of California, Berkeley, 2121 Berkeley Way, Rm no 5302, Berkeley, CA 94720-7360, USA; email: jvr@berkeley.edu 